\title{
PENGARUH PENERAPAN E-FILING, PENGETAHUAN PAJAK DAN SANKSI PAJAK TERHADAP KEPATUHAN WAJIB PAJAK PADA PEGAWAI KEMENDIKBUD
}

\author{
Yetti Mulyati $^{(1)}$, Juli Ismanto ${ }^{(2)}$ \\ Fakultas Ekonomi dan Bisnis Universitas Pamulang \\ july.ismanto@gmail.com
}

\begin{abstract}
This study aims to determine the effect of the application of E-Filing, tax knowledge, and tax sanctions on taxpayer compliance in the Ministry of Education and Culture's employees of the P4TK business and tourism units (Center for Development, Empowerment of Educators and Education Personnel). The research method used is the quantitative method. The sample in the study was 146 respondents. Data collection techniques using a questionnaire. The analysis technique used is through validity test, reliability test, and path analysis. The results of the study show that all variables of E-Filing Implementation, Tax Knowledge, Tax Sanctions have a significant positive effect on Taxpayer Compliance. This shows that the variability of the dependent variable can be explained by the independent variable by $60 \%$, the remaining $40 \%$ is explained by the variability of other variables outside the research model. Social learning and behavioral attribution can increase taxpayer awareness that is carried out within the Employee Development and Empowerment Center for Educators and Education Personnel (P4TK) for the Jabodetabek Region. The obligation to submit annual income tax returns, adequate tax knowledge, and sanctions are also a guarantee that the provisions of tax laws will be complied with.
\end{abstract}

Keywords: Application of E-Filing;Tax Knowledge; Tax Sanctions; Taxpayer Compliance.

\begin{abstract}
Abstrak
Penelitian ini bertujuan untuk mengetahui pengaruh penerapan E-Filing, pengetahuan pajak dan sanksi pajak terhadap kepatuhan wajib pajak pada Pegawai Kemendikbud unit bisnis dan pariwisata P4TK (Pusat Pengembangan, Pemberdayaan Pendidik dan Tenaga Kependidikan). Metode penelitian yang digunakan yaitu metode kuantitatif. Sampel dalam penelitian sebanyak 146 responden. Teknik pengumpulan data menggunakan kuesioner. Teknik analisis yang digunakan melalui uji validitas, uji reliabilitas, serta analisis jalur. Hasil penelitian menunjukan semua variable Penerapan E-Filing, Pengetahuan Pajak, Sanksi Pajak signifikan berpengaruh positif terhadap Kepatuhan Wajib Pajak. Hal ini menunjukkan bahwa variabilitas variabel dependen dapat dijelaskan oleh
\end{abstract}


variabel independen sebesar $60 \%$ sisanya sebesar $40 \%$ dijelaskan oleh variabilitas variabel-variabel lain di luar model penelitian. Pembelajaran sosial dan atribusi perilaku dapat meningkatkan kesadaran wajib pajak dijalankan di lingkungan Pegawai Pusat Pengembangan dan Pemberdayaan Pendidik dan Tenaga Kependidikan (P4TK) Wilayah Jabodetabek. Kewajiban menyampaikan pemberitahuan tahunan pajak penghasilan, pengetahuan pajak yang memadai, serta sanksi juga merupakan jaminan ketentuan perundangan perpajakan akan dipatuhi.

Kata kunci: Penerapan E-Filing; Pengetahuan Pajak; Sanksi Pajak; Kepatuhan Wajib Pajak.

\section{PENDAHULUAN}

Pembangunan pada hakikatnya adalah pembaharuaan yang berkesinambungan mencapai keadaan yang dianggap lebih baik. Pembangunan dilaksanakan melalui rangkaian investasi yang hanya terwujud dengan dukungan dana yang besar. Dana tersebut diperoleh melalui berbagai sumber yaitu pemerintah ataupun swasta, baik dalam negeri maupun mancanegara, dan salah satunya berasal dari perolehan pajak. Peran Pajak sangat penting untuk negara. Pendapatan didapat dari pajak masuk dalam kas negara digunakan untuk keperluan pembangunan publik seperti seperti pembiayaan kepentingan masyarakat, pendidikan, kesehatan, pensiun dan transportasi umum. Boleh dikatakan bahwasannya pajak adalah dana yang didapat dari rakyat untuk rakyat (Amalia \& Hapsari, 2018; Mahardika, 2019). Menurut undang-undang nomor 28 Tahun 2007 (Presiden RI, 2007) Tentang perubahan ketiga atas undang-undang nomor 6 Tahun 1983 Tentang ketentuan umum dan tata cara perpajakan meyebutkan bahwa Pajak adalah kontribusi wajib bagi warga negara yang terutang oleh pribadi atau badan yang bersifat memaksa berdasarkan undang-undang, dengan tidak mendapatkan imbalan secara langsung dan digunakan untuk keperluan negara bagi sebesar- besarnya kemakmuran rakyat.

Direktorat Jenderal Pajak Kementerian Keuangan (Kemenkeu) mencatatkan realisasi pelaporan Surat Pemberitahuan (SPT) Tahunan 2020 Rasio Kepatuhan Wajib Pajak (WP) meningkat. Jumlah Surat Pemberitahuan Tahunan (SPT) Pajak Penghasilan (PPh) yang diterima pada 2020 sebanyak 14,76 juta. Angka ini sebesar $78 \%$ dari jumlah WP yang wajib memasukkan SPT, naik dari tahun sebelumnya yang sebesar 73\%. Namun demikian, rasio Kepatuhan WP (Wajib Pajak) meleset dari yang ditargetkan sebesar 80\% (Jayani \& Ridhoi, 2021). 


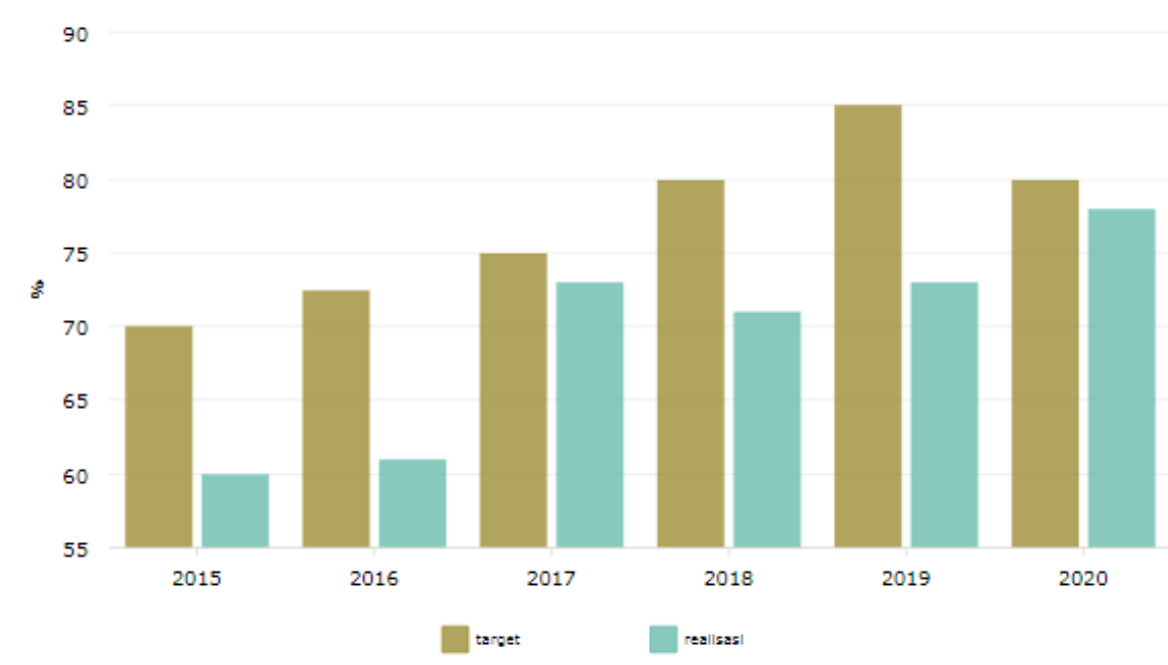

Sumber: Kementrian Keuangan (Kemenkeu), Januari 2020 (Jayani \& Ridhoi, 2021)

\section{Gambar 1. Target dan Realisasi Rasio Kepatuhan Wajib Pajak Penghasilan}

Peningkatan kepatuhan wajib pajak secara formal penyampaian surat pemberitahuan Tahunan pajak (SPT) penghasilan 2020 hanya terjadi pada wajib pajak (WP) orang pribadi karyawan. Tahun lalu, Wajib Pajak orang pribadi karyawan dalam penyampaian SPT sebanyak 12,1 juta WP (Wajib Pajak) atau $85,42 \%$ dari total jumlah Wajib Pajak orang pribadi karyawan yang wajib melaporkan SPT yaitu sebanyak jumlah 14,17 juta Wajib Pajak. Persentase ini lebih tinggi dibandingkan tahun sebelumnya 2019 sebesar 73,2\%. "Kelompok karyawan memiliki tingkat kepatuhan pajak yang lebih tinggi daripada kelompok wajib pajak lainnya," Kementerian Keuangan pada laporan APBN KiTa edisi Februari 2021(M. Wildan, 2021). Sementara itu, kepatuhan Wajib Pajak formal badan dan Wajib Pajak orang pribadi nonkaryawan tahun sebelumnya justru melempem. Rasio kepatuhan Wajib Pajak formal badan tahun sebelumnya hanya $60,17 \%$ lebih rendah dari rasio 2019 sebesar 65,28\%.(M. Wildan, 2021).

Fenomena menunjukkan realisasi tingkat kepatuhan wajib pajak masih rendah dilihat dalam pelaporan Surat Pemberitahuan (SPT) Tahunan hingga 1 April 2019 mencapai 11,309 juta wajib pajak. Cakupan realisasi ini adalah wajib pajak orang pribadi maupun badan. Porsentase jumlah pelaporan sebesar $61,7 \%$ dari total 18,334 juta wajib pajak yang seharusnya melaporkan SPT Tahunan. ujar Direktur Eksekutif Center for Indonesia Taxation Analysis (CITA) Yustinus Prastowo berpendapat nilai realisasi ini menunjukkan tingkat kepatuhan wajib pajak masih rendah. "Kepatuhan formal masih cukup rendah. Ini (saja) baru tingkat kepatuhan menyampaikan SPT, belum kepatuhan materiil yakni mengenai kebenaran dalam pengisian SPT", ujarnya (Uly, 2019).

Penggunaan sistem self assessment merupakan sebuah sistem reformasi yang dilakukan menggantikan sistem official assessment yang berlaku sebelumnya oleh Direktorat Jenderal Pajak (Saksama, 2018). Sistem self assessment adalah sistem dimana Wajib Pajak diberi kepercayaan untuk menghitung dan melaporkan sendiri pajak yang terutang oleh Wajib Pajak, sedangkan petugas pajak sendiri bertugas

* Corresponding author’s e-mail: july.ismanto@gmail.com 
untuk mengawasinya (Direktorat Jendral Pajak, 2009). Peningkatan kemudahan administrasi khususnya layanan elektronik (e-registration, e-filing, e-payment, dan $e$-withholding), meningkatkan kapasitas dan kapabilitas infrastruktur sistem teknologi dan kualitas basis data perpajakan, melanjutkan revisi regulasi termasuk pengaturan prosedur pemajakan e-commerce, dan meningkatkan kolaborasi dan sinergi dengan instansi, lembaga, asosiasi usaha, dan pihak ketiga lainnya terus diupayakan oleh pihak DJP (Direktorat Jendral Pajak).

Iklim kepatuhan dan kesadaran pemenuhan kewajiban perpajakan, tercermin dalam situasi dimana wajib pajak paham dan mengetahui atau berusaha untuk memahami semua ketentuan peraturan perundang-undangan perpajakan, kepatuhan sebagai fondasi self assessment dapat dicapai melalui elemen kunci secara efektif dalam penerapannya. Elemen-elemen kunci yakni program pelayanan yang baik kepada wajib pajak, prosedur yang sederhana dan memudahkan wajib pajak, program pemantauan kepatuhan dan verifikasi yang efektif, dan pemantapan sanksi (law enforcement) secara tegas dan adil (Avianto et al., 2016).

Avianto et al., 2016; Rinaningsih, 2018 , menyatakan terdapat beberapa faktor yang mendukung pelaksanaan penerapan layanan elektronik khususnya e-filing dalam pelaporan SPT Tahunan. Faktor-faktor tersebut yaitu; a) Kesadaran wajib pajak itu sendiri; b) Keinginan Mencoba; c) Sosialisasi dan; d) Jaringan Internet. Faktor lain nya yang menghambat pelaksanaan penerapan layanan e-filing dalam pelaporan SPT tahunan antara lain: a) Pengetahuan Wajib Pajak; b) Jaringan Internet dan; c) Meyakinkan Wajib Pajak. Keberhasilan atau tidaknya sistem ini ditentukan oleh kepatuhan sukarela Wajib Pajak serta pengawasan secara optimal aparat pajak (Iswari Anggit, 2019).

Beberapa penelitian mengenai kepatuhan wajib Pajak maka diketahui beberapa faktor yang mempengaruhi kepatuhan wajib pajak itu sendiri antara lain pengetahuan, pemahaman perpajakan, kesadaran wajib pajak, sanksi perpajakan, penerapan dalam kemudahan administrasi layanan elektronik termasuk jaringan internet (e-registration, e-filing, e-payment, dan e-withholding) (Abadi, 2017; Amalia \& Hapsari, 2018; Andela \& Irawati, 2020; Avianto et al., 2016; Dewi \& Merkusiwati, 2018; Diantini et al., 2018; Eka Dwi Jayanti, 2017; Firdaus, 2019; Hartanti \& Husein, 2018; Husnurrosyidah \& Suhadi, 2017; Marliana et al., 2015; Paramartha \& Rasmini, 2016; Rinaningsih, 2018; Setiawan \& Barlian, 2017; Siamena et al., 2017; Wardani \& Asis, 2017; Wicaksono et al., 2018). Adapun faktor tersebut berlaku pada semua lapisan masyarakat maupun badan dalam membayar pajak.

Penelitian ini memilih Pusat Pengembangan dan Pemberdayaan Pendidik dan Tenaga Kependidikan (disingkat P4TK) se Jabodetabek, dimana salah satu Unit Pelaksana Teknis (UPT) yang berada di bawah koordinasi Kementerian Pendidikan dan Kebudayaan Indonesia. Terdapat permasalahan yang berkaitan dengan pelaporan pajak melalui sarana e-filling, salah satunya ketidak tepatan waktu pelaporan melalui sarana on-line system dan tidak mengerti dan memahami dalam pengetahuan perhitungan pajak bahkan dengan tidak adanya sanksi bagi mereka bila tidak melaporkan pajak. Tujuan penelitian ini untuk meninjau dan uji ulang kembali terhadap konsistensi hasil dari penelitian sebelumnya oleh (Abadi, 2017;

* Corresponding author's e-mail: july.ismanto@gmail.com 
Amalia \& Hapsari, 2018; Avianto et al., 2016; Diantini et al., 2018; Firdaus, 2019; Marliana et al., 2015; Wardani \& Asis, 2017) menunjukan hasil yang berbeda.

Tabel 1. Laporan SPT Pegawai ASN P4TK (Pusat Pengembangan, Pemberdayaan Pendidik dan Tenaga Kependidikan)

\begin{tabular}{ccccc} 
NO & $\begin{array}{c}\text { SPT Pajak } \\
\text { Periode } \\
\text { Tahun }\end{array}$ & $\begin{array}{c}\text { Jumlah } \\
\text { Pegawai } \\
(\mathbf{2 3 0} \text { orang) }\end{array}$ & Prosentase & Keterangan \\
\hline 1 & $2015 / 2016$ & $75 / 230$ & $33 \%$ & Nilai belum \\
2 & $2016 / 2017$ & $70 / 230$ & $30 \%$ & mencapai $100 \%$ \\
3 & $2017 / 2018$ & $85 / 230$ & $37 \%$ & \\
\hline
\end{tabular}

Sumber: diolah oleh penulis (2019)

\section{KERANGKA TEORITIS DAN PENGEMBANGAN HIPOTESIS}

\section{Teori Atribusi}

Teori atribusi dapat menjelaskan sikap wajib pajak terhadap peraturan perpajakan. Terdapat dua sumber atribusi bagaimana sikap wajib pajak tersebut terbentuk yaitu atribusi internal dan atribusi eksternal. Menurut Menurut Darwati (2015) dalam (F. F. Wildan \& Sulistiyanti, 2017) bahwasannya atribusi internal adalah perilaku seseorang disebabkan kekuatan dalam diri individu atau unsur psikologis mendahului suatu perilaku, sedangkan atribusi eksternal merupakan perilaku individu disebabkan kekuatan diluar diri individu itu sendiri (environmental forces).

\section{Teori Pembelajaran Sosial}

Teori pembelajaran sosial merupakan penjelasan bagaimana seorang dapat belajar secara langsung melalui proses pengamatan dan pengalaman. Teori ini menjelaskan mengenai tingkah laku manusia bukan semata karena reflek atau stimulus, melainkan reaksi yang timbul diakibatkan adanya interaksi antara lingkungan dengan kognitif manusia. Bandura (1977) dalam (F. F. Wildan \& Sulistiyanti, 2017) dalam teorinya, mejelaskan bahwa terdapat empat proses dalam pembelajaran sosial meliputi: 1) Proses Perhatian (attentional); 2) Proses Penahanan (retention); 3) Proses Reproduksi Motorik. 4) Proses Penguatan (reinforcement).

\section{Kepatuhan Wajib Pajak}

Kepatuhan wajib pajak memiliki pengertian iklim kepatuhan dan kesadaran pemenuhan kewajiban perpajakan, tercermin dalam situasi dimana wajib pajak paham atau berusaha untuk memahami semua ketentuan peraturan perundangundangan perpajakan (Avianto et al., 2016). Menurut Mukhlis dan Simanjutak dalam (Amalia \& Hapsari, 2018) kepatuhan Wajib Pajak merupakan suatu keadaan

* Corresponding author's e-mail: july.ismanto@gmail.com 
dimana Wajib Pajak bertanggung jawab menetapkan sendiri kewajiban perpajakan kemudian secara akurat dan tepat waktu dalam membayar dan melaporkan pajaknya. Indikator Kepatuhan Wajib Pajak tercermin dalam: 1) Aspek ketepatan waktu: merupakan presentase pelaporan SPT yang disampaikan tepat waktu sesuai dengan ketentuan yang berlaku; 2) Aspek Income atau penghasilan Wajib Pajak: merupakan kesediaan membayar kewajiban angsuran Pajak Penghasilan (PPh) sesuai ketentuan yang berlaku; 3) Aspek law enforcement: merupakan pembayaran tunggakan pajak yang ditetapkan berdasarkan Surat Ketetapan Pajak (SKP) sebelum jatuh tempo; 4) Aspek pembayaran: merupakan menyetor atau membayar pajak yang terutang ke Kantor Pos, Bank yang telah ditetapkan atau ditunjuk oleh Menteri Keuangan

\section{E-Filing}

E-Filling adalah suatu cara penyampaian SPT atau penyampaian Pemberitahuan Perpanjangan SPT Tahunan secara elektronik dilakukan secara online yang real time melalui website Direktorat Jenderal Pajak (Direktorat Jendral Pajak, 2009). Menurut Haryadi dalam (Amalia \& Hapsari, 2018) menyatakan bahwa indikator e-filling adalah sebagai berikut: 1) Keamanan dan kerahasiaan merupakan seberapa kuatnya perangkat teknologi untuk menjaga keamanan dan kerahasiaan data Wajib Pajak; 2) Kesiapan teknologi informasi Merupakan sekumpulan sumber daya informasi organisasi, peran penggunaannya, serta manajemen yang menjalankannya apakah sudah kompeten di bidangnya; 3) Persepsi pengguna merupakan ukuran penggunaan teknologi dapat dipercaya akan mendatangkan manfaat bagi penggunanya; 4) Persepsi kemudahan suatu ukuran sebuah system dengan mudah di pahami untuk digunakan.

\section{Pengetahuan Pajak}

Rahayu dalam (Amalia \& Hapsari, 2018) pengetahuan perpajakan merupakan kemampuan Wajib Pajak untuk mengetahui aturan perpajakan baik itu soal tarif pajak berdasarkan Undang-Undang yang akan mereka bayar maupun manfaat pajak berguna bagi kehidupan mereka. Pengetahuan perpajakan atau pemahaman perpajakan yang dimiliki oleh Wajib Pajak harus meliputi: 1) Pengetahuan mengenai Ketentuan Umum dan Tata Cara Perpajakan; 2) Pengetahuan mengenai sistem perpajakan di Indonesia; 3) Pengetahuan mengenai fungsi perpajakan.

\section{Sanksi Pajak}

Mardiasmo dalam (Amalia \& Hapsari, 2018) menjelaskan mengenai sanksi perpajakan adalah jaminan ketentuan peraturan perundang-undangan perpajakan dalam norma perpajakan akan dituruti, ditaati, dipatuhi. Adapun Indikator dari sanksi perpajakan, yaitu: 1) Keterlambatan melaporkan dan membayarkan pajak harus dikenai sanksi; 2) Tingkat penerapan sanksi; 3) Sanksi digunakan untuk meningkatkan kepatuhan Wajib Pajak; 4) Penghapusan sanksi meningkatkan kepatuhan Wajib Pajak.

\section{Kerangka Pemikiran}


Dengan mempelajari tinjauan literature dari beberapa dasar teori yang ada serta berdasarkan rumusan masalah yang telah dijelaskan dalam pembahasan pendahuluan sebelumnya, maka kerangka pemikiran penelitian ini digambarkan pada Gambar 2 berikut ini:

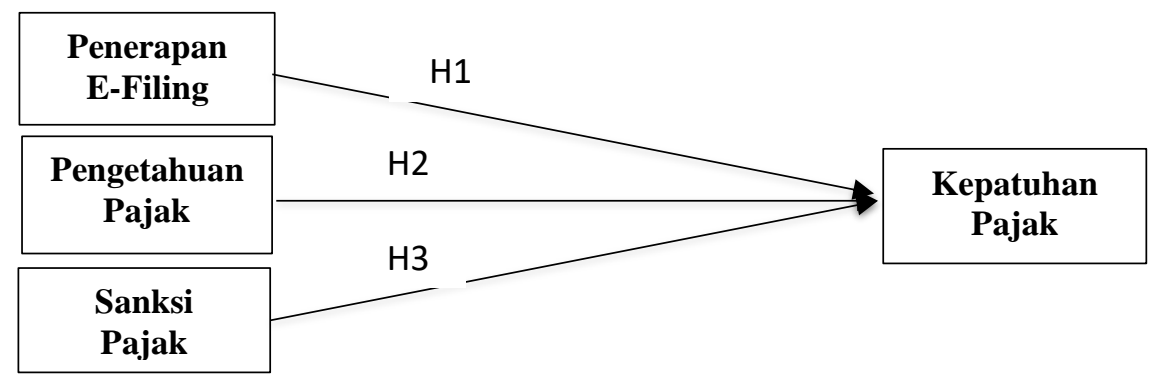

\section{Gambar 2. Kerangka Pemikiran}

\section{Hipotesis Penelitian}

Hipotesis dalam penelitian ini:

1. Penerapan E-Filling berpengaruh signifikan terhadap Kepatuhan Wajib Pajak pada pegawai kantor Pusat Pengembangan dan Pemberdayaan Pendidik dan Tenaga Kependidikan (P4TK) se Jabodetabek.

2. Pengetahuan Perpajakan berpengaruh signifikan terhadap Kepatuhan Wajib Pajak pada pegawai kantor Pusat Pengembangan dan Pemberdayaan Pendidik dan Tenaga Kependidikan (P4TK) se Jabodetabek.

3. Sanksi Pajak berpengaruh signifikan terhadap Kepatuhan Wajib Pajak pada pegawai kantor Pusat Pengembangan dan Pemberdayaan Pendidik dan Tenaga Kependidikan (P4TK) se Jabodetabek.

\section{METODE RISET}

\section{Klasifikasi Sampel}

Populasi dalam penelitian ini adalah wajib pajak yang berada di Kantor Pusat Pengembangan dan Pemberdayaan Pendidik dan Tenaga Kependidikan (P4TK) yang berada di sekitar wilayah Jabodetabek yang terdiri dari P4TK Bahasa, P4TK Pendidikan Jasmani dan Bimbingan Konseling, P4TK Bisnis dan Pariwisata. Responden yang dijadikan sebagai objek penelitian adalah wajib pajak pribadi yang bersedia untuk membantu peneliti dalam menyelesaikan penelitian. Metode pengambilan sampel yang digunakan adalah metode convenience (convenience sampling), yaitu suatu metode di mana sampel dipilih karena mudah dijangkau. Sampel convenience adalah suatu metode sampel non probabilitas, artinya tiap unit populasi tidak memiliki kesempatan untuk dipilih sebagai sampel penelitian. Sampel yang diambil atau terpilih dikarenakan sampel tersebut ada pada waktu dan tempat yang tepat. Penentuan ukuran sampel dari suatu populasi digunakan rumus Slovin (Sugiyono, 2017). 
Tabel 2. Populasi Pegawai Pusat Pengembangan dan Pemberdayaan Pendidik dan Tenaga Kependidikan (P4TK) Wilayah Jabodetabek

\begin{tabular}{llc}
\multicolumn{1}{c}{ Kantor } & \multicolumn{1}{c}{ Alamat Kantor } & Jumlah Pegawai \\
\hline P4TK Bahasa & Jalan Gardu RT.10/ RW.02, Srengseng & 70 \\
& Sawah, Jagakarsa, RT.10/RW.2, & \\
& Srengseng Sawah, Jagakarsa, Kota & \\
& Jakarta Selatan, Daerah Khusus Ibukota & \\
& Jakarta 12640 & \\
P4TK Penjas dan & $\begin{array}{l}\text { Lebak wangi, Jl. Raya Parung No.420, } \\
\text { Pemagarsari, Parung, Bogor, West Java }\end{array}$ \\
BK & 16330 & \\
P4TK Bisnis dan & $\begin{array}{l}\text { Jl. Raya Parung KM. 22-23, Bojongsari, } \\
\text { Pariwisata }\end{array}$ & Bojongsari Baru, Bojongsari, Kota \\
& Depok, Jawa Barat 16516 & \\
& Total & 230 \\
\hline
\end{tabular}

Data Primer Diolah 2019

Tabel 2. memperlihatkan sebaran populasi pegawai pusat pengembangan dan pemberdayaan pendidik dan tenaga kependidikan (P4TK) wilayah Jabodetabek. Berdasarkan persamaan Slovin besarnya sample responden sebanyak 146 responden dengan kata lain ukuran populasi $(\mathrm{N})$ sebesar 230 orang dengan presisi ditetapkan diantara $\mathrm{e}=5 \%$ (persen kelonggaran atau ketidaktelitian karena kesalahan pengambilan sampel yang dapat ditolerir atau dinginkan) didapatkan hasil sebanyak 146 responden.

\section{Data Penelitian.}

Data yang digunakan dalam penelitian ini adalah data primer yang di dapatkan secara langsung dengan menyebarkan kuesioner kepada responden, berisi pertanyaan-pertanyaan yang harus dijawab oleh responden dan mengambil kembali kuesioner secara langsung. Tehnik analisis data yang digunakan peneliti adalah tehnik analisis kuantitatif yaitu analisis terhadap data yang diberikan skor sesuai dengan skala pengukuran yang ditetapkan (skala likert). Metode statistik menggunakan tekhnik regresi dengan Software Warp-PLS.

\section{ANALISIS DATA DAN PEMBAHASAN}

\section{Hasil Penelitian}

\section{Deskripsi Variabel Penelitian}

Analisis deskriptif diolah untuk menggambarkan persepsi responden terhadap pertanyaan kuisioner yang berhubungan dengan pertanyaan dalam variable 
penelitian. Perhitungan dalam analisis deskriptif melalui porsentase jawaban responden dengan menggunakan nilai rata-rata (mean) dari setiap indikator yang diajukan peneliti, selanjutnya dilakukan interpretasi persepsi responden dengan menggunakan kriteria three box method (Ferdinand 2006 dalam Husnurrosyidah \& Suhadi, 2017). Adapun peng-kriteriaan disebutkan $1.0-2.3=$ rendah; $2.4-3.7$ =sedang; dan $3.8-5.0=$ tinggi. Selanjutnya berdasarkan kriteria tersebut ditentukan indeks persepsi terhadap responden terhadap variable penelitian sebagai berikut;

Tabel 3. Descriptive Statistics

\begin{tabular}{llllll} 
& N & Minimum & Maximum & Mean & $\begin{array}{l}\text { Std. } \\
\text { Deviation }\end{array}$ \\
\hline Kepatuhan WP & 146 & 2.75 & 5 & 3.4709 & 0.53135 \\
EFiling & 146 & 2.6 & 5 & 3.3575 & 0.5906 \\
Sanksi Pajak & 146 & 2 & 5 & 3.5776 & 0.62058 \\
Pengetahuan Pajak & 146 & 2.5 & 5 & 3.476 & 0.52385 \\
\hline
\end{tabular}

Data Primer Diolah 2019

Berdasarkan hasil tabel 3 menunjukan bahwa persepsi jawaban mengenai variable Kepatuhan, E-Filing, Sanksi Pajak, dan Pengetahuan Pajak dijelaskan dalam pengkatagorian sedang.

\section{Pengujian Validitas dan Reliabilitas Konstruk}

Pengujian Latent variable coefficients merupakan salah satu hal terpenting dalam pengujian Validitas dan Reliabilitas Konstruk yang wajib di sampaikan dengan menggunakan warpPLS dan diperoleh hasil sebagai berikut;

\begin{tabular}{lcccc} 
& Tabel 4 & & \\
& $\begin{array}{c}\text { Latent variable coefficients } \\
\text { Patuh P }\end{array}$ & E_Filing & Sanksi_P & P_Pajak \\
\hline R-squared & 0.6 & & & \\
Composite reliab & 0.8 & 0.8 & 0.8 & 0.8 \\
Cronbach's alpha & 0.6 & 0.8 & 0.6 & 0.7 \\
Avg.var.extrac & 0.5 & 0.5 & 0.5 & 0.5 \\
Full collin.VIF & 2.1 & 1.6 & 1.5 & 1.4 \\
$Q$-squared & 0.6 & & & \\
\hline Data Primer Diolah 2019 & & &
\end{tabular}

Pengujian tabel 4 melalui prosedur SEM-PLS, maka evaluasi validitas konvergen konstruk menggunakan Average variance Extracted (AVE) yang mana kriteria tersebut di atas 0.50 (Fornell dan Lacker, 1981 dalam Solihin \& Ratmono, 2013) maka didapatkan hasil output pada tabel 4, variable Kepatuhan Wajib Pajak, Penerapan E-Filing, Sanksi dan Pengetahuan bernilai di atas 0.50, kriteria tersebut telah terpenuhi. Adapun nilai $Q$-squared (biasanya disebut Stoner-Geiser 
Coefficient) sebagai ukuran nonparamaterik sering digunakan sebagai penilaian validitas prediktif atau relevansi menunjukan bahwasannya validitas prediktif di nilai baik dalam penelitian ini karena bernilai di atas nol (yaitu 0.6). Adapun hasil penelitian reliabilitas yang menyajikan dua ukuran reliabilitas instrument penelitian composite reability bernilai di atas 0.7 dan cronbach's alpha bernilai di atas 0.6 sebagai syarat reliabilitas (Fornell dan Lacker, 1981; Nunnaly, 1978 dalam Solihin \& Ratmono, 2013). Hasil penelitian ini menunjukan bahwasanya instrument reliabilitas terpenuhi.

Penelitian Full Collinearity VIF juga merupakan pengujian kolineritas penuh meliputi multikolineritas vertical dan lateral didapatkan hasil nilai Full Collinearity VIF kurang dari 3.3 sehingga model bebas dari masalah kolineritas vertical, lateral dan common method bias. Dalam kriteria full collinearity test bernilai lebih kecil dari 3.3 (Kock, 2013 dalam Solihin \& Ratmono, 2013).

\section{Menilai Keseluruhan Model (Goodness of Fit)}

Tabel 5. Goodness Of Fit

Model fit indices and $P$ values

\begin{tabular}{ll}
\hline APC $=0.324$ & $\mathrm{P}<0.001$ \\
ARS $=\mathbf{0 . 5 9 9}$ & $\mathrm{P}<0.001$ \\
AVIF $=\mathbf{1 . 4 1 6}$ & Good if $<5$ \\
\hline
\end{tabular}

Data Primer Diolah 2019

Pengujian model disajikan pada Tabel 5 menunjukan goodness of fit model telah memenuhi kriteria dengan estimasi model nilai APC sebesar 0.324 dan ARS 0.599 serta signifikan. Nilai AVIF sebesar 1.416. Peng-kriteriaan goodness of fit terpenuhi bila nilai p untuk APC dan ARS lebih kecil nilainya dari 0.05, berarti hasil didapatkan signifikan, selain itu AVIF menjadi indikator multikolineritas nilainya lebih kecil dari 5 (Solihin \& Ratmono, 2013) atau dengan kata lain penelitian ini menunjukan goodness of fit model telah memenuhi kriteria.

\section{Pengujian Model dan Hasil Hipotesis}

Berikut adalah gambar pengujian model hasil penerapan $e$-filing, pengetahuan pajak dan sanksi pajak terhadap kepatuhan wajib pajak: 


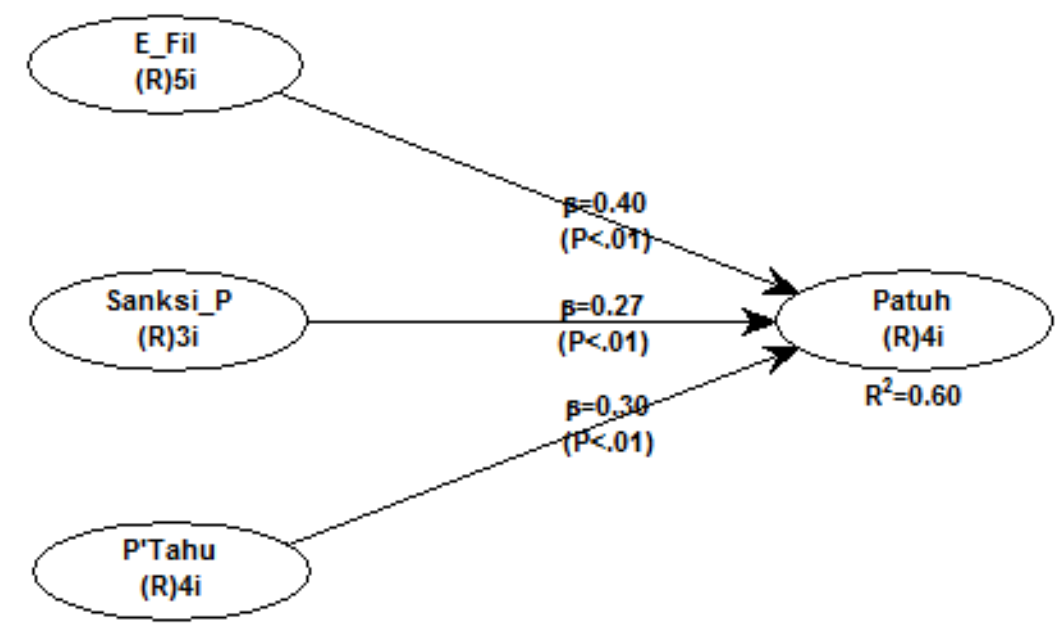

Data Primer Diolah 2019

\section{Gambar 3. Direct Efffect penerapan e-filing, pengetahuan pajak dan sanksi pajak terhadap kepatuhan wajib pajak.}

Berdasarkan hasil pengujian hipotesis dengan menggunakan WarpPLS maka didapatkan hasil terlihat pada tabel 6 sebagai berikut;

\section{Tabel 6 \\ Direct Effect dan Hipotesis}

\begin{tabular}{llccl}
\multirow{2}{*}{ No } & Jalur & \multicolumn{2}{c}{ Direct Effect } & Keterangan \\
& & Koefisien & p-value & \\
\hline $\mathbf{1}$ & E-Filing Terhadap Kepatuhan WP & 0.40 & $<.01$ & Hipotesis diterima \\
$\mathbf{2}$ & Pengetahuan Terhadap Kepatuhan WP & 0.30 & $<.01$ & Hipotesis diterima \\
$\mathbf{3}$ & Sanksi Terhadap Kepatuhan WP & 0.27 & $<.01$ & Hipotesis diterima \\
\hline
\end{tabular}

Data Primer Diolah 2019

Hasil pengujian dilihat dalam tabel 6 menunjukkan koefisien direct effect variabel e-filing terhadap kepatuhan wajib pajak sebesar 0,40 dengan tingkat signifikansi sebesar <.01, sehingga dapat dikatakan hipotesis pertama dapat diterima. Sedangkan variabel Pengetahuan Pajak terhadap Kepatuhan Wajib Pajak menunjukkan koefisien direct effect sebesar 0,30 dengan tingkat signifikansi sebesar <.01, sehingga dapat dikatakan hipotesis 2 dapat diterima. Untuk variabel Sanksi Pajak terhadap kepatuhan Wajib Pajak menunjukan koefisien direct effect sebesar 0.27 dengan tingkat signifikansi sebesar <.01, maka dapat dikatakan-pula hipotesis ketiga diterima. 


\section{Uji Koefisien Determinasi (Nagelkerke's $\mathbf{R}^{2}$ )}

Uji ini untuk mengetahui seberapa besar variabilitas variabel-variabel independen mampu memperjelas variabilitas variabel dependen. Koefisien determinasi regresi Warp-PLS dilihat dengan nilai Nagelkerke $R$ Square. Nilai Nagelkerke $R$ Square meng-interpretasikan i nilai $R$ Square pada regresi berganda (Ghozali, 2006). Berdasarkan Tabel4. Latent variable coefficients disampaikan sebelumnya menunjukkan nilai Nagelkerke's R2 sebesar 0,60. Hal ini menunjukkan variabilitas variabel dependen dapat dijelaskan oleh variabel independen adalah sebesar $60 \%$, sisanya sebesar $40 \%$ dijelaskan oleh variabilitas variabel-variabel lain di luar model penelitian.

\section{Pembahasan Hasil Penelitian}

\section{Pengaruh E-Filling Terhadap Kepatuhan Wajib Pajak.}

Hasil pengujian dengan menggunakan regresi SEM-PLS pada Tabel 6 menunjukan nilai koefisien E-Filing sebesar 0.40 dengan signifikansi sebesar <.01. karena signifikan lebih kecil dari 0.05 maka hipotesis pertama dinyatakan E-filing mempunyai pengaruh signifikan terhadap Kepatuhan Wajib Pajak. Kewajiban menyampaikan Pemberitahuan Tahunan Pajak Penghasilan Wajib Pajak Orang Pribadi Aparatur Sipil Negara penerapannya di lingkungan Pegawai Pusat Pengembangan dan Pemberdayaan Pendidik dan Tenaga Kependidikan (P4TK) Wilayah Jabodetabek melalui E-Filing sudah diterapkan.

Hasil penelitian ini mendukung penelitian yang dilakukan (Abadi, 2017; Amalia \& Hapsari, 2018; Avianto et al., 2016; Dewi \& Merkusiwati, 2018; Diantini et al., 2018; Hartanti \& Husein, 2018; Wicaksono et al., 2018) menunjukan hasil yang sama yaitu Penerapan Sistem E-Filling berpengaruh signifikan terhadap kepatuhan wajib pajak. Hasil penelitian tersebut dinyatakan semakin baik penerapan $e$-filling maka kepatuhan Wajib Pajak akan meningkat.

Sedangkan penelitian (Firdaus, 2019; Marliana et al., 2015; Wardani \& Asis, 2017) sebaliknya tidak sejalan dimana Penerapan Sistem E-Filling tidak berpengaruh signifikan terhadap kepatuhan wajib pajak dikarenakan Kendala pada penerapan aplikasi $e$ - filing yang dialami Wajib Pajak di antaranya adalah kurangnya sosialisasi pemahaman masyarakat terhadap modernisasi perpajakan khususnya pelaporan SPT Tahunan melalui $e$-filing

Teori Atribusi menyatakan perilaku seseorang bisa disebabkan oleh kekuatan diri individu dan perilaku seorang individu yang disebabkan oleh kekuatan-diluar (environmental forces). Indikasi berhasil atau tidaknya sistem ini sangat ditentukan oleh kepatuhan sukarela para Wajib Pajak dan pengawasan yang optimal dari aparat pajak sendiri penerapan layanan e-filing dalam pelaporan SPT tahunan yaitu: a) Persepsi Wajib Pajak; b) Jaringan Internet dan keamanan; c) Meyakinkan Wajib Pajak. 


\section{Pengaruh Pengetahuan Pajak Terhadap Kepatuhan Wajib Pajak.}

Hipotesis Kedua menyatakan bahwa Pengetahuan Pajak berpengaruh terhadap Kepatuhan Wajib Pajak. Tabel 6 menunjukan nilai koefisien Pengetahuan terhadap kepatuhan Pajak sebesar 0.30 dengan signifikansi sebesar <.01. karena signifikan lebih kecil dari 0.05 maka hipotesis kedua yang menyatakan Pengetahuan mempunyai pengaruh signifikan terhadap Kepatuhan Wajib Pajak.

Hasil penelitian ini mendukung dengan penelitian yang dilakukan (Dewi \& Merkusiwati, 2018; Hartanti \& Husein, 2018; Paramartha \& Rasmini, 2016; Wicaksono et al., 2018) dalam penelitian tentang Pengetahuan Perpajakan Terhadap Kepatuhan Wajib Pajak didapatkan hasil Pengetahuan Perpajakan berpengaruh positif dan signifikan terhadap kepatuhan Wajib Pajak. Sebaliknya Penelitian ini tidak sejalan penelitian yang dilakukan oleh (Amalia \& Hapsari, 2018; Avianto et al., 2016; Rinaningsih, 2018) yang mana banyak pengguna internet tidak semua memiliki pengetahuan untuk melaksanakan $e$-filing.

Hal ini menunjukkan semakin banyaknya pengetahuan perpajakan yang diketahui oleh wajib pajak maka semakin tinggi kesadaran yang dimiliki wajib pajak sehingga dapat meningkatkan kepatuhan wajib pajak dalam memenuhi kewajiban perpajakannya, sebaliknya jika semakin sedikit pengetahuan perpajakan yang diperoleh wajib pajak maka semakin rendah pula kesadaran wajib pajak sehingga dapat menurunkan kepatuhan wajib pajak dalam memenuhi kewajiban perpajakannya.

Teori pembelajaran sosial juga menjelaskan bagaimana seorang dapat belajar secara langsung melalui proses pengamatan dan pengalaman pribadi seseorang dalam pengetahuan perpajakan yang memadai sehingga akan patuh dalam melaksanakan kewajiban perpajakannya.

\section{Pengaruh Sanksi Pajak Terhadap Kepatuhan Wajib Pajak.}

Hipotesis Ketiga menyatakan bahwa Sanksi Pajak berpengaruh terhadap Kepatuhan Wajib Pajak. Tabel 6 menunjukan nilai koefisien E-Filing sebesar 0.27 dengan signifikansi sebesar <.01. karena signifikan lebih kecil dari 0.05 maka hipotesis ketiga yang menyatakan Sanksi Pajak berpengaruh signifikan terhadap Kepatuhan Wajib Pajak.

Hasil penelitian ini juga mendukung penelitian yang dilakukan (Dewi \& Merkusiwati, 2018; Hartanti \& Husein, 2018; Paramartha \& Rasmini, 2016; Siamena et al., 2017; Wicaksono et al., 2018) dimana didapatkan hasil penelitian terdapat hubungan yang signifikan dan positif antara sanksi perpajakan dengan kepatuhan wajib pajak orang pribadi. Begitupula sebaliknya penelitian ini tidak mendukung penelitian (Abadi, 2017; Amalia \& Hapsari, 2018) yang mana hasil penelitiannya menunjukan wajib pajak tidak pernah tahu akan wujud konkret imbalan dari uang yang mereka bayarkan Disini dapat dilihat sanksi pajak dinilai masih belum kuat untuk menekan kemauan dan inisiatif masyarakat untuk takut apabila tidak membayar kewajiban perpajakannya sesuai peraturan yang berlaku.

* Corresponding author's e-mail: july.ismanto@gmail.com 
Teori atribusi dapat menjelaskan sikap wajib pajak terhadap peraturan perpajakan. Sikap perilaku seseorang tersebut disebabkan unsur psikologis dan perilaku individu tersebut bisa juga disebabkan kekuatan diluar diri dari individu sendiri. Hal ini berarti bila sanksi perpajakan diberlakukan akan menjadi jaminan bahwa ketentuan perundang-undangan perpajakan atau norma perpajakan akan dituruti, ditaati dan dipatuhi. Sanksi perpajakan merupakan pencegah agar wajib pajak tidak melanggar norma perpajakan yang berlaku.

\section{KESIMPULAN DAN SARAN}

Kesimpulan dalam penelitian menyatakan bahwasannya E-filing mempunyai pengaruh signifikan terhadap Kepatuhan Wajib Pajak melalui indikator penilaian keamanan, teknologi informasi dan persepsi pengguna. Adapun Pengetahuan Perpajakan mempunyai pengaruh signifikan terhadap Kepatuhan Wajib Pajak melalui indikator penilaian ketentuan umum dan tata cara perpajakan. Sedangkan untuk Sanksi Perpajakan mempunyai pengaruh signifikan terhadap Kepatuhan Wajib Pajak melalui indikator penilaian dalam melaporkan, membayarkan dan tingkat penerapan sanksi pada Pegawai Kemendikbud Unit Bisnis dan Pariwisata P4TK (Pusat Pengembangan, Pemberdayaan Pendidik dan Tenaga Kependidikan).

Hasil penelitian mengindikasikan pembelajaran sosial melalui pengamatan, pengalaman seseorang, serta atribusi perilaku dalam diri maupun dari luar diri dapat meningkatkan kesadaran wajib pajak dan kepatuhan perpajakan dapat dijalankan. Peraturan (MENPAN_RB, 2015) dalam Surat Edaran Nomor 8 Tahun 2015 mengenai Kewajiban Penyampaian Surat Pemberitahuan Tahunan Pajak Penghasilan Wajib Pajak Orang Pribadi Aparatur Sipil Negara (ASN)/Anggota Tentara Nasional Indonesia (TNI) /Kepolisian Republik Indonesia (POLRI) bisa diterapkan di lingkungan Pegawai Pusat Pengembangan dan Pemberdayaan Pendidik dan Tenaga Kependidikan (P4TK) Wilayah Jabodetabek.

Keterbatasan penelitian yang dihadapi adalah Populasi dalam penelitian ini terpusat di Kantor Pusat Pengembangan dan Pemberdayaan Pendidik dan Tenaga Kependidikan (P4TK) yang berada di sekitar wilayah Jabodetabek. Serta banyaknya variabel independent yang digunakan terbatas hanya E-Filing, Pengetahuan dan Sanksi Pajak.

Saran pengembangan penelitian selanjutnya dapat memasukkan variabel lain yang secara teoritis diduga mempengaruhi Kepatuhan Wajib Pajak, seperti menambahkan variable layanan elektronik lainnya seperti e-registration, $e$ payment, dan $e$-withholding dan menggunakan objek yang lebih luas sehingga hasil penelitian dapat memperoleh perbandingan antara tiap jenis Kepatuhan Wajib Pajak yang berbeda.

\section{DAFTAR PUSTAKA}

Abadi, R. (2017). Pengaruh Sanksi Pajak, Kualitas Pelayanan dan Penerapan

* Corresponding author's e-mail: july.ismanto@gmail.com 
Sistem E-Filing Terhadap Kepatuhan Wajib Pajak Orang Pribadi (Studi Empiris Wajib Pajak Orang Pribadi yang Terdaftar di KPP Pratama1 Padang). Jurnal Akuntansi Universitas Negeri Padang, 1-20. http://ejournal.unp.ac.id/students/index.php/akt/article/view/2630

Amalia, A. R., \& Hapsari, D. W. (2018). Pengaruh Implementasi E-Filing, Pengetahuan Perpajakan, dan Sanksi Perpajakan Terhadap Kepatuhan Wajib Pajak Orang Pribadi Pada Pelaporan Surat Pemberitahuan (Studi Kasus pada Kantor Dinas Pendidikan dan Kebudayaan Kabupaten Tegal). E-Proceeding of Management, 59(2), 5164-5165. https://doi.org/10.13541/j.cnki.chinade.2012.10.004

Andela, A. P., \& Irawati, W. (2020). Pengaruh Persepsi Kegunaan, Keamanan dan Kerahasiaan Serta Kesiapan Teknologi Informasi terhadap Intensitas Penggunaan E-Filing. Ekopreneur, 2(1), 1-15. http://openjournal.unpam.ac.id/index.php/EPR/article/view/8440

Avianto, G. D., Rahayu, S. M., \& Kaniskha, B. (2016). Analisa Peranan E-Filing Dalam Rangka Meningkatkan Kepatuhan Pelaporan Surat Pemberitahuan Tahunan Wajib Pajak Orang Pribadi (Studi Pada Kantor Pelayanan Pajak Pratama Malang Selatan). IJurnal Perpajakan (JEJAK), 9, 1-8. http://perpajakan.studentjournal.ub.ac.id/index.php/perpajakan/article/view/2 $61 / 256$

Dewi, S. K., \& Merkusiwati, N. K. L. A. (2018). Pengaruh Kesadaran Wajib Pajak, Sanksi Perpajakan, E-Filing, dan Tax Amnesty Terhadap Kepatuhan Pelaporan Wajib Pajak. E-Jurnal Akuntansi, 22(02), 1626. https://doi.org/10.24843/EJA.2018.v22.i02.p30

Diantini, A., Yasa, I. N. P., \& Atmadja, A. T. (2018). Pengaruh Penerapan E-Filing Terhadap Kepatuhan Wajib Pajak Orang Pribadi (Studi Pada Kantor Pelayanan Pajak Pratama Singaraja). JIMAT (Jurnal Ilmiah Mahasiswa Akuntansi) Universitas Pendidikan Ganesha, 9(1), 55-64. https://ejournal.undiksha.ac.id/index.php/S1ak/article/view/20435

Direktorat Jendral Pajak. (2009). Undang-undang Nomor 16 Tahun 2009 (Undangundang KUP). https://www.kemenkeu.go.id/sites/default/files/uu-kup mobile.pdf

Eka Dwi Jayanti. (2017). Penggaruh Penerapan Sistem E-Filing, Pemahaman Perpajakan dan Kesadaran Wajib Pajak Terhadap Kepatuhan Wajib Pajak. EPrint STIE Perbanas, 1-20. http://eprints.perbanas.ac.id/2667/1/ARTIKEL ILMIAH.pdf

Firdaus, A. S. (2019). Penerapan E-Filing Terhadap Kepatuhan Wajib Pajak Orang Pribadi Dalam Penyampaian SPT Tahunan (Studi Kasus Pada KPP Pratama Pamekasan). Skripsi Fakultas Ekonomi Dan Bisnis Universitas Airlangga Surabaya. http://repository.unair.ac.id/86679/1/abstrak.pdf

Ghozali, I. (2006). Aplikasi Analisis Mutivariat dengan Program SPSS (Cetakan IV). Undip. 
Jurnal Akuntansi Berkelanjutan Indonesia - Vol. 4, No. 2, Mei 2021 - Mulyati \& Ismanto

Hartanti, E., \& Husein, S. (2018). Pengaruh Penerapan Sistem e-Filing , Pengetahuan Pajak , dan Sanksi Pajak Terhadap Kepatuhan Wajib Pajak Orang Pribadi. Issn 2356 - 4385, 5(1), 37-42. http://research.kalbis.ac.id/Research/Files/Article/Full/Q9ZSEQVAIMJDGR Q8D89CK79JP.pdf

Husnurrosyidah, \& Suhadi. (2017). Pengaruh E-Filing, e-Billing dan e-Faktur Terhadap Kepatuhan Pajak pada BMT Se-Kabupaten Kudus. Jurnal Analisa Akuntansi Dan Perpajakan, 1(1), 97-106.

Iswari Anggit. (2019). Kepatuhan Pajak di Indonesia Masih Rendah. CNBC Indonesia. $\quad$ https://www.cnbcindonesia.com/news/20190326160157-463008/aviliani-kepatuhan-pajak-di-indonesia-masih-rendah

Jayani, D. H., \& Ridhoi, M. A. (2021). Rasio Kepatuhan Wajib Pajak PPh pada 2020 Meleset dari Target. Katadata.Co.Id.

Mahardika, I. (2019). Manajemen Pajak (Cetakan Pe). Quadrant Yogyakarta.

Marliana, R., Suherman, M., \& Almunawwaroh, M. (2015). Pengaruh Penerapan E-Filing Terhadap Kepatuhan Wajib Pajak Dalam Penyampaian Surat Pemberitahuan (SPT) Tahunan Pada Kantor Pelayanan Pajak Pratama Kota Tasikmalaya. Media Riset Akuntansi, Auditing \& Informasi, 15(1). https://media.neliti.com/media/publications/52705-ID-pengaruh-penerapane-filingn-terhadap-ke.pdf

MENPAN_RB. (2015). Kewajiban Penyampaian Surat Pemberitahuan Tahunan Pajak Penghasilan Wajib Pajak Orang Pribadi Oleh Aparatur Sipil Negara/Anggota Tentara Nasional Indonesia/Kepolisian Republik Indonesia Melalui E-Filing. http://pati.kemenag.go.id/pict/8476395SE MenpanRB 8_2015 kewajiban eFiling.pdf

Paramartha, I. P. I. P., \& Rasmini, N. K. (2016). Pengaruh Kualitas Pelayanan, Pengetahuan dan Sanksi Perpajakan Pada Kepatuhan Wajib Pajak Badan. EJurnal Akuntansi Universitas Udayana, 15(1), 641-666.

Presiden RI. (2007). UNDANG-UNDANG REPUBLIK INDONESIA NOMOR 28 TAHUN 2007 TENTANG PERUBAHAN Presiden RI. (2007). UNDANGUNDANG REPUBLIK INDONESIA NOMOR 28 TAHUN 2007 TENTANG PERUBAHAN. http://www.dpr.go.id/dokjdih/document/uu/UU_2007_28.pdf

Rinaningsih. (2018). Tinjauan Ketentuan Atas Kewajiban E-Filing Dalam Penyampaian SPT Tahunan PPH Bagi ASN/Anggota TNI/POLRI. Simposium Nasional Keuangan Negara, 2009, 79-96. https://jurnal.bppk.kemenkeu.go.id/snkn/article/download/256/113/

Saksama, H. Y. (2018). Kepatuhan dan Penerimaan Pajak 2017 Tumbuh Pesat, DJP Optimis Hadapi 2018. https://www.pajak.go.id/kepatuhan-danpenerimaan-pajak-2017-tumbuh-pesat-djp-optimis-hadapi-2018

Setiawan, D. R., \& Barlian, A. (2017). Pengaruh Penerapan Sistem E-Filing dan Kesadaran Wajib Pajak Terhadap Kepatuhan Wajib Pajak Orang Pribadi

* Corresponding author’s e-mail: july.ismanto@gmail.com 
Pada KPP Pratama Jakarta Gambir Tiga Tahun 2016. https://stiami.ac.id/index.php/download/get/317/penelitian-dodi-r-setiawan

Siamena, E., Sabijono, H., \& Warongan, J. D. . (2017). Pengaruh Sanksi Perpajakan dan Kesadaran Wajib Pajak Terhadap Kepatuhan Wajib Pajak Orang Priibadi di Manado. Riset Akuntansi Going Concern, 12(2), 917-927. https://ejournal.unsrat.ac.id/index.php/gc/article/view/18367/17895

Solihin, M., \& Ratmono, D. (2013). Analisis SEM-PLS dengan WarpPLS 3.0. Andi Yogyakarta.

Sugiyono. (2017). Metode Penelitian Kombinasi (Mixed Methods) (Eds.9). ALFABETA, cv.

Uly, Y. A. (2019). Pelaporan SPT Baru 61,7\%, Tingkat Kepatuhan Wajib Pajak Rendah. $\quad$ Economy.Okezone.Com. https://economy.okezone.com/read/2019/04/02/20/2038285/pelaporan-sptbaru-61-7-tingkat-kepatuhan-wajib-pajak-rendah

Wardani, D. K., \& Asis, M. R. (2017). Pengaruh Pengetahuan Wajib Pajak, Kesadaran Wajib Pajak, dan Program SAMSAT CORNER Terhadap Kepatuhan. Akuntansi Dewantara, 1(2), 106-116. http://jurnal.ustjogja.ac.id/index.php/akuntansidewantara/article/view/1488/p df

Wicaksono, R. A., Nazar, M. R., \& Kurnia. (2018). Pengaruh Sanksi Perpajakan, Kualitas Pelayanan, dan Pengetahuan Wajib Pajak Terhadap Kepatuhan Wajib Pajak ( Studi Pada Wajib Pajak Orang Pribadi Non Karyawan Yang Melakukan Usaha Dan Pekerjaan Bebas Di KPP Pratama Sumedang Tahun $2017 \quad$ ). E-Proceeding of Management, 5(1), 820-827. https://libraryeproceeding.telkomuniversity.ac.id/index.php/management/arti cle/view/6311/6290

Wildan, F. F., \& Sulistiyanti, U. (2017). Analisis Determinan Kepatuhan Wajib Pajak Orang Pribadi Di Kabupaten Bantul. Jurnal Riset Manajemen Sekolah Tinggi Ilmu Ekonomi Widya Wiwaha Program Magister Manajemen, 4(2), 113-125. https://doi.org/10.32477/jrm.v4i2.254

Wildan, M. (2021). Kepatuhan Formal Wajib Pajak Badan dan OP Nonkaryawan Menurun. News.Ddtc.Co.Id. https://news.ddtc.co.id/kepatuhan-formal-wajibpajak-badan-dan-op-nonkaryawan-menurun-28058 